\title{
A influência do Design na leitura da informação digital sobre saúde e bem-estar em ambientes organizacionais
}

\author{
The influence of Design in the reading of digital information \\ about health and wellness in organizational environments
}

\author{
Fernanda Rodrigues Bertoldo, Ivette Kafure Muñoz, Ana Mansur de Oliveira, \\ Virgínia Tiradentes Souto
}

Design da informação; comunicação organizacional; leitura digital; Informação sobre saúde e bem-estar; estudos de usuário

A velocidade da transmissão das informações cresce de forma acelerada. Somado a isso, as recentes transformações sociais relacionadas a forma de trabalhar, estudar e se comunicar geram sobrecarga cognitiva. Assim, informações que abordam temas de saúde e bem-estar tornam-se cada vez mais relevantes para o aumento da capacidade de adaptação diante das frequentes mudanças, especialmente em ambientes organizacionais onde a habilidade cognitiva é altamente demandada. O objetivo deste trabalho é investigar a influência do design da informação para a leitura de informações digitais sobre saúde e bem-estar, disponibilizadas em contextos organizacionais. O design da informação é abordado neste trabalho como auxiliar da leitura digital. Com esta finalidade, o estudo analisou as reações e opiniões de dois grupos de pessoas que receberam informações sobre o ciclo do sono, com duas diferentes representações. De acordo com os resultados, o grupo que leu a informação representada a partir de um infográfico apresentou maior eficiência e satisfação com a informação do que o grupo que fez a leitura da informação representada somente por texto.

Information design; organizational communication; digital reading; health and wellness information; user studies

The speed of information transmission are growing at an accelerated rate. In addition, the recent social changes related to the way of working, studying and communicating generate cognitive overload. In this way, information that addresses health and wellness issues becomes increasingly relevant for increasing the capacity for adaptation in the face of frequent changes, especially in organizational environments where cognitive ability is highly demanded. The objective of this work is to investigate the influence of information design for reading digital information about health and wellness, made available in organizational contexts. Information design is approached in this work as an auxililary to digital reading. For this purpose, the study analyzed the reactions and opinions of two groups of people who received information about the sleep cycle, with two different representations. According to the results, the group that read the information represented from an infographic demonstrated greater efficiency and satisfaction with the information design than the group that read the information represented only by text.

Anais do $10^{\circ} \mathrm{CIDI}$ e $10^{\circ} \mathrm{CONGIC}$

Kelli C.A.S. Smythe, Rafael de Castro Andrade (orgs.)

Sociedade Brasileira de Design da Informação - SBDI

Curitiba | Brasil | 2021
Proceedings of the $10^{\text {th }} \mathrm{CIDI}$ and $10^{\text {th }} \mathrm{CONGIC}$

Kelli C.A.S. Smythe, Rafael de Castro Andrade (orgs.)

Sociedade Brasileira de Design da Informação - SBDI Curitiba | Brazil | 2021 


\section{Introdução}

A informação digital ocupa um espaço cada vez maior nos contextos informacionais da sociedade, seja por meio das possibilidades que a internet introduziu como redes sociais, sites e aplicativos, seja por meio do acesso a informações estáticas em smartphones e computadores pessoais, como documentos e arquivos. A afirmação de Capurro (2007), sobre a importância da característica digital da informação no contexto social, torna-se cada vez mais relevante quando o autor alega que "é lugar comum considerar-se a informação como condição básica para o desenvolvimento econômico juntamente com o capital, o trabalho e a matériaprima, mas o que torna a informação especialmente significativa na atualidade é a sua natureza digital" (Capurro, 2007, p. 02).

O recente e atual cenário ocasionado pela pandemia do COVID-19, acelerou transformações nas relações sociais, especialmente nas relações de trabalho. Tal fato, obrigou organizações públicas e privadas a adotarem o trabalho remoto como principal modalidade, quando possível. Diante disso, a informação em telas de computadores e celulares tornou-se, então, a principal ou, por um período, a única forma de estabelecer relações, tanto pessoais quanto profissionais.

Em um contexto no qual as relações acontecem cada vez mais mediadas por artefatos digitais, a informação clara, estruturada e objetiva torna-se imprescindível para a melhor comunicação entre os diversos atores envolvidos em um processo comunicacional. Somado a isso, o volume de informações cresce de forma acelerada e, conforme destaca Araújo (2018), "a chamada 'explosão da informação' do pós-segunda guerra não pode ser comparada, em volume e intensidade, com a revolução causada pela expansão dos computadores pessoais, da internet e dos smartphones no final do século XX e início do século XXI" (p. 06).

Ao analisar este panorama de excesso de informação, Han (2016) atribui à comunicação digital a característica de um vírus contagioso, pois se produz imediatamente no plano emocional e afetivo. "Não pressupõe uma leitura, porque esta só é passível de uma aceleração limitada. Uma informação ou um conteúdo, ainda que de pouca significação, pode difundir-se rapidamente na rede, como uma epidemia ou pandemia" (Han, 2016, p. 69). O escritor chama de fadiga da informação uma doença psíquica causada pelo excesso de informação, que conduz à atrofia do pensamento a partir de "uma paralisia crescente da capacidade analítica, perturbações da atenção, ansiedade geral ou incapacidade de assumir responsabilidades" (Han, 2016, p. 74).

Em linha com as inquietações do filósofo Han, Wurman (1991) utiliza o termo ansiedade de informação para expressar o resultado da distância cada vez maior entre o que compreendemos e o que achamos que deveríamos compreender. $\mathrm{O}$ autor explica que há um buraco negro entre dados e conhecimento, que ocorre quando a informação não nos diz o que queremos ou precisamos saber.

Os termos utilizados pelos autores refletem uma estreita relação entre o excesso de informação e questões relacionadas à saúde e bem-estar do usuário da informação. A comparação da velocidade da transmissão da informação a um vírus contagioso ou a uma 
pandemia, bem como os vocábulos fadiga e ansiedade associados à palavra informação, retratam as dificuldades enfrentadas pelos indivíduos na atualidade, quando expostos a um crescente volume informacional.

Em ambientes organizacionais a demanda pela rapidez em assimilar informações e manter um nível de desempenho crescente pode ser ainda maior. Assim, quando informações relacionadas à saúde e bem-estar são compartilhadas pelas instituições, muitas vezes não são priorizadas pelo leitor que, na maioria das vezes, está imerso em informações relacionadas à execução do trabalho.

Diante do excesso de estímulos informacionais ocasionado pela velocidade de transmissão da informação digital e intensificado pela virtualização das relações, sejam elas pessoais ou profissionais, a organização e o design da informação podem ser vistos como ferramentas de auxílio na leitura, especialmente em contextos que requerem agilidade e pouco tempo de dedicação a ela. $\mathrm{Na}$ área do design da informação, o uso de infográfico, além de tornar a informação mais atrativa, pode auxiliar o leitor a compreender algo que, comunicado de outra maneira, seria complexo demais. Lima (2015) escolhe o conceito de "tradução" para expressar a ideia do que representa um infográfico: uma abordagem gráfica adequada à informação. Já Cairo (2016) entende que o propósito dos infográficos é iluminar as pessoas, não as entreter ou vender serviços e ideias, mas informá-las.

Assim, a problemática objeto deste artigo pode ser resumida na seguinte questão: a informação representada por infográfico pode influenciar na leitura da informação digital sobre saúde e bem-estar, em ambientes organizacionais? Com o objetivo de ampliar o interesse e a leitura de informações que promovam saúde e bem-estar, em contextos organizacionais, este trabalho realizou um estudo comparativo entre a informação representada em texto e a informação organizada em infográfico. Desta forma, uma informação relacionada ao ciclo do sono foi apresentada com dois tipos de design diferentes para dois grupos distintos de servidores públicos de uma mesma organização.

\section{Informação digital, saúde e bem-estar}

A mídia digital contribui para uma mudança transformadora na leitura. Liu (2005) lista uma série de vantagens da leitura em mídia digital em relação ao ambiente impresso, como: interatividade, não linearidade, velocidade no acesso à informação e a fluência entre texto e imagens, áudio e vídeo.

Por outro lado, são observadas mudanças de comportamentos relacionadas à qualidade da leitura. Wolf (2019) utiliza a expressão "olhar calmo" para expressar preocupações em relação ao leitor do século XXI. A autora observa este novo leitor com um olhar inquieto, com uma mente que atende a diversos estímulos, como um beija-flor atraído pelos néctares e cuja capacidade de atenção está sendo prejudicada de forma sutil, com consequências imprevisíveis.

A pesquisadora reflete sobre a possibilidade de que a habilidade de percepção esteja efetivamente caindo devido ao excesso de informações e considera o vício na estimulação 
sensorial intensificado. Wolf (2019) acrescenta que este fenômeno é impulsionado por ambientes contemporâneos que nos impõem estímulos sensoriais exagerados não apenas durante o dia, mas, também, frequentemente à noite, que está cada vez mais encurtada devido à atenção direcionada aos dispositivos digitais.

Este encurtamento da noite, mencionado por Wolf (2019), remete a questões relacionadas ao sono, frequentemente associadas, entre outros fatores, ao consumo exagerado de informações em meios digitais. Crary (2014) afirma que pesquisas recentes mostram o crescimento exponencial do número de pessoas que acordam uma ou mais vezes durante a noite para consultar mensagens ou acessar seus dados. Um comportamento chamado de sleep mode, que evidencia de que forma a presença constante de estímulos tende a impedir o desligamento do indivíduo.

A relação entre informação digital e questões pertinentes ao sono motivou a escolha do tema apresentado aos participantes deste estudo. Todos receberam informações sobre o ciclo do sono ao responder o questionário. Corroborando com essa relação, Márquez (2018) explica que, ultimamente, fala-se em um novo tipo de "insônia tecnológica" que associa o uso prolongado do telefone celular (e outros dispositivos tecnológicos, como computadores e tablets) a casos de insônia, gerando um duplo vício: tecnológico e farmacológico. Marquez afirma ainda que, a luz artificial emitida por dispositivos móveis pode alterar a produção de melatonina - hormônio que auxilia a regular o ritmo circadiano e a adormecer.

Ainda sobre o comportamento de leitura em telas, Liu (2005), estudioso da informação digital, explica que mais tempo é gasto na navegação e digitalização, localização de palavraschave, leitura única, leitura não linear e leitura mais seletiva, enquanto menos tempo é gasto em leitura em profundidade e concentrada. Nessa direção, Wolf (2019) menciona alguns estudos relacionados a mudanças na maneira como os leitores captam a sequência dos detalhes de um enredo e, possivelmente, da estrutura lógica de um argumento. Os estudos citados revelaram, por exemplo, que o sequenciamento da informação e a lembrança dos detalhes foram prejudicados na leitura em tela.

A transição da leitura para um formato digital, os novos comportamentos dos leitores e os diferentes contextos em que o usuário está imerso ao interagir com uma informação demandam adaptações, também, na forma como a informação é disponibilizada ao usuário. As pesquisas de Liu (2005) e Wolf (2019) apontam para mudanças no comportamento do usuário da informação que, possivelmente, requeiram modificações na representação da informação para este novo leitor.

\section{O usuário da comunicação organizacional no teletrabalho}

Olhar para as necessidades do usuário da informação tornou-se tão ou mais importante que olhar para a própria informação. Sem o receptor, a informação perde sua finalidade. Davenport (1998), destaca que nosso fascínio pela tecnologia nos fez esquecer o objetivo principal da informação: informar. Informar algo a alguém. $O$ autor reflete sobre a importância do interesse 
dos usuários para a relevância dos computadores, já que, por exemplo, se os funcionários de uma empresa não compartilham a informação que possuem, esta perde o valor. Davenport (1998) ressalta, então, o papel fundamental das pessoas na atmosfera informacional.

Ao olhar para o usuário da informação em contextos organizacionais nos tempos atuais, percebe-se uma mudança significativa, tanto na atmosfera informacional que o envolve quanto no comportamento do próprio usuário como leitor. O trabalho remoto, que passou a fazer parte da realidade de grande parte das organizações públicas e foi reforçado durante a atual pandemia, é um direcionador da transformação do contexto e do perfil do usuário da informação em ambientes organizacionais. As informações circulam entre os colaboradores da organização mediadas em sua totalidade por uma tela de computador ou celular.

Ao analisar a gestão da informação nas organizações, Davenport (1998) acrescenta que temos acesso a uma quantidade de informações muito além da nossa capacidade de atenção (Figura 1) e ressalta o surgimento de novas fontes e novos meios a todo o tempo e os antigos, como livros e correspondência em papel, continuam existindo.

Figura 1: Fontes de informações. Adaptada de Davenport (1998)

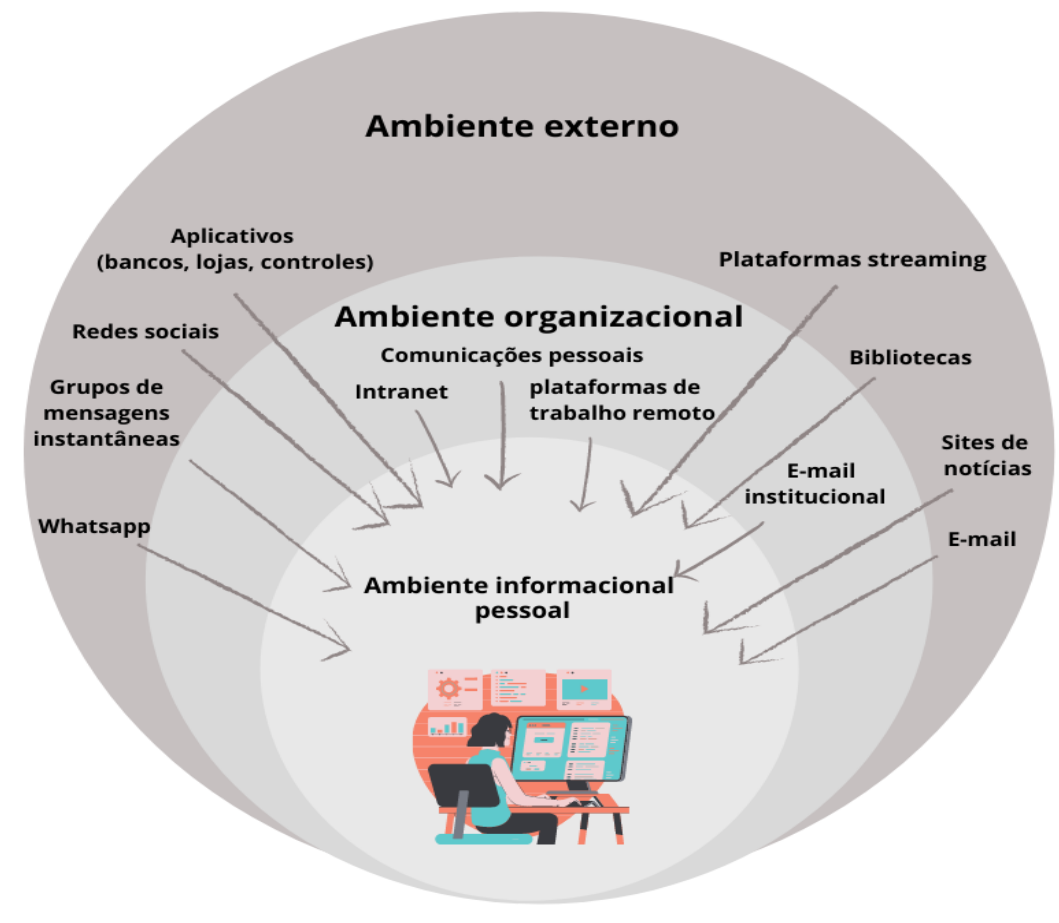

A atenção, sob a perspectiva da interação humano-computador, é entendida por Jacko (2012), como o aumento da conscientização direcionada a um determinado evento ou ação para selecioná-lo com o objetivo de aumentar o processamento e ampliar a compreensão do evento, realizar uma ação ou melhorar a memória para o evento. Assim, apesar da inquestionável importância das informações que tratam do tema saúde e bem-estar, há possibilidade de não receberem a atenção necessária ou priorização do usuário, que está concentrado em demandas profissionais. Jacko (2012) explica que a atenção nos permite filtrar 
informações desnecessárias para que possamos nos concentrar em um aspecto específico que seja relevante para nossos objetivos.

Nesse sentido, as informações de saúde e bem-estar podem não ser consideradas necessárias ou relevantes para o alcance dos objetivos do leitor, naquele contexto. Por esse motivo, capturar a atenção para uma informação pode envolver questões como esforço cognitivo, tempo demandado para a leitura e a usabilidade da informação. Ao receber uma informação planejada e organizada conforme os fundamentos do design, o usuário pode perceber uma experiência de leitura mais satisfatória e agradável, que demanda menos esforço cognitivo e, em consequência, menor tempo para leitura e compreensão.

\section{Design da informação e usabilidade}

Há diversos conceitos utilizados para expressar o significado do Design da Informação e, na maior parte deles, observa-se a presença das palavras planejamento e organização. Segundo Pettersson (2002) o design da informação compreende análise, planejamento, apresentação e compreensão de uma mensagem - seu conteúdo, linguagem e forma. Para o autor, independentemente do meio selecionado, um material de informação bem projetado irá satisfazer os requisitos estéticos, econômicos, ergonômicos, bem como os de assunto. Frascara (2011) acrescenta que o design da informação, deve garantir a efetividade das comunicações a partir da facilitação de processos de percepção, leitura, compreensão, memorização e uso da informação apresentada.

A usabilidade, um orientador importante para o design da informação, também é destacada por Jacko (2012) ao explicar que "qualquer forma de design eficaz é resultado de um estudo rigoroso, uma preocupação com a organização e usabilidade combinada com o conhecimento dos princípios básicos de design de harmonia, equilíbrio e simplicidade" (p. 320). As definições da ISO 9241, abordam a usabilidade como uma medida que avalia critérios de eficácia, eficiência e satisfação de usuários específicos em um contexto específico de uso.

Para Frascara (2011) o design da informação deve, geralmente, ajudar na tomada de decisões e na execução de ações e observa, ainda, a motivação do leitor e seu repertório individual como aspectos atuantes no processo informacional. Além da clareza expositiva e coerência interna, Frascara $(2011$, p. 23) ressalta "a motivação do leitor, seus conhecimentos que lhe permitem compreender a informação em questão, as ações pelas quais o leitor obtém a informação, e as ações que eventualmente devem seguir de acordo com as informações obtidas".

Os princípios do design da informação fornecem insumos para que a informação proporcione uma boa experiência de uso aos usuários. Para Petterson (2016), os princípios do design informacional devem contribuir para a eficiência no design e desenvolvimento de informações e os define da seguinte forma:

- Princípios funcionais: definição do problema, provisão de estrutura, provisão de clareza, provisão de simplicidade, provisão de ênfase, provisão de unidade. 
- Princípios administrativos: acesso à informação, custos de informação, ética da informação, qualidade da segurança.

- Princípios estéticos: harmonia, proporção estética.

- Princípios cognitivos: facilidade de atenção, facilidade de percepção, facilidade de processamento, facilidade de memória.

A conexão existente entre os princípios do design da informação e a usabilidade pode ser considerada a partir dos cinco atributos da usabilidade, definidos por Nielsen (1993): facilidade de aprendizagem; eficiência; facilidade de memorização; baixa taxa de erros e satisfação. O atendimento aos princípios de design, definidos por Pettersson (2016), poderia ser relacionado ao alcance dos atributos de Nielsen, conforme sugere-se na Tabela 1:

Tabela 1: Princípios do Design e atributos de usabilidade de Nielsen. Elaborada pelas autoras.

\begin{tabular}{ll}
\hline Princípios do Design da Informação & Atributos de usabilidade Nielsen (1993) \\
\hline $\begin{array}{l}\text { Princípios funcionais: definição do problema, } \\
\text { estrutura, clareza, simplicidade, ênfase e unidade }\end{array}$ & $\begin{array}{l}\text { Facilidade de aprendizagem e memorização, } \\
\text { baixa taxa de erros, Satisfação }\end{array}$ \\
\hline $\begin{array}{l}\text { Princípios administrativos: acesso à informação, } \\
\text { custos de informação, ética da informação, }\end{array}$ & Eficiência e baixa taxa de erros, Satisfação \\
qualidade da segurança & \\
\hline Princípios estéticos: harmonia, proporção estética & Satisfação \\
\hline Princípios cognitivos: facilidade de atenção, & $\begin{array}{l}\text { Facilidade de aprendizagem e memorização, } \\
\text { percepção, processamento e memória }\end{array}$ \\
\hline
\end{tabular}

Lopez (2004) ressalta que alguns estudos relacionados à qualidade da informação em saúde na internet vêm sendo realizados, desde a década de 90 , e utilizam, dentre outras, as categorias design, interatividade e conteúdo como indicadores de qualidade da informação. A pesquisa realizada por Eysenbach e Köhler (2002), por exemplo, indicou que os critérios mais frequentemente usados para análise da qualidade de informações em saúde na internet foram os de acurácia, completeza, legibilidade, design, informações do provedor da página e as referências bibliográficas.

\section{Estudo empírico}

Diante dos conceitos apresentados e com o intuito de verificar as diferentes reações e experiências de uso na leitura da informação digital sobre saúde e bem-estar, o estudo comparou duas representações de informações sobre um mesmo tema: o ciclo do sono. Os dados coletados se relacionam ao interesse e estímulo da leitura das informações 
apresentadas, à facilidade de compreensão da informação, à possibilidade de mudança de comportamento a partir da leitura e à avaliação da apresentação da informação.

\section{Caracterização do grupo de foco}

A pesquisa contou com a participação de dez servidores públicos que atuam no Tribunal de Justiça do Distrito Federal e Territórios - TJDFT. Dentre os participantes, 7 são do sexo feminino e 3 do sexo masculino, com uma faixa etária média de 44 anos. Cinquenta por cento ocupam cargos de gestão na organização. Quanto ao perfil dos usuários que responderam ao instrumento, todos exercem suas atividades profissionais pela modalidade de teletrabalho e utilizam com frequência o computador, e não tablets ou celulares, para a execução de suas atividades.

Quanto ao acesso à intranet do órgão, local onde as informações sobre saúde e bem-estar são divulgadas, $60 \%$ dos indivíduos pesquisados, informaram que acessam diariamente. Por outro lado, dentre os 10 participantes, apenas 1 informou que lê com frequência as informações sobre saúde e bem-estar disponibilizadas no canal de comunicação mencionado. Ou seja, os usuários acessam o canal de comunicação, mas não são atraídos por informações sobre saúde e bem-estar. Sobre este ponto, é oportuno destacar que as informações que abordam dicas de saúde no site do TJDFT são apresentadas em formato exclusivamente textual, seguindo o mesmo padrão de design da informação demonstrado na figura 2 .

\section{Método de estudo}

Os participantes receberam o link, enviado por e-mail, para acesso ao questionário elaborado na ferramenta forms da Microsoft. Todos foram convidados a realizar a leitura do arquivo que continha a informação sobre o ciclo do sono, para responder ao instrumento. A primeira representação (Figura 2), disponível no site do TJDFT para acesso público, foi enviada para um grupo de cinco pessoas em formato inteiramente textual.

Figura 2: O ciclo do sono. Fonte: www.tjdft.jus.br
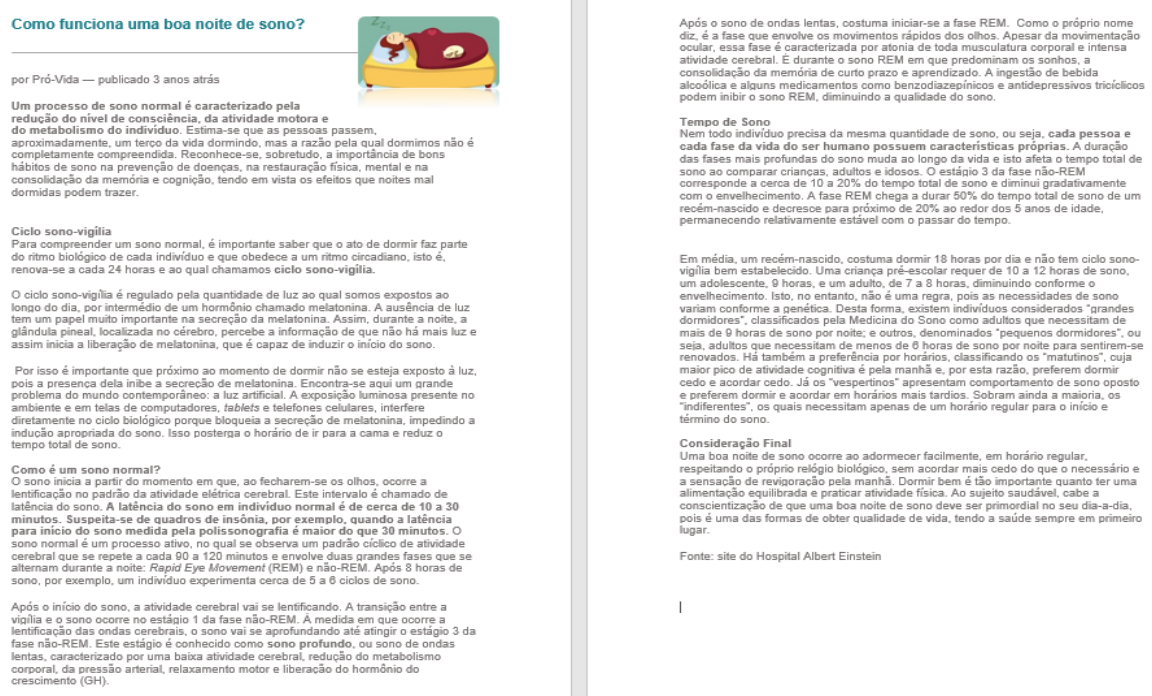
A segunda informação (Figura 3) foi representada por meio de um infográfico e apresentada ao segundo grupo, também composto por cinco pessoas.

Figura 3: O ciclo do sono. Adaptado de Nassau (2019).

\section{CICLO DO SONO}

4 a 6 ciclos por noite $\longrightarrow$ cada ciclo: 90 a 120 min

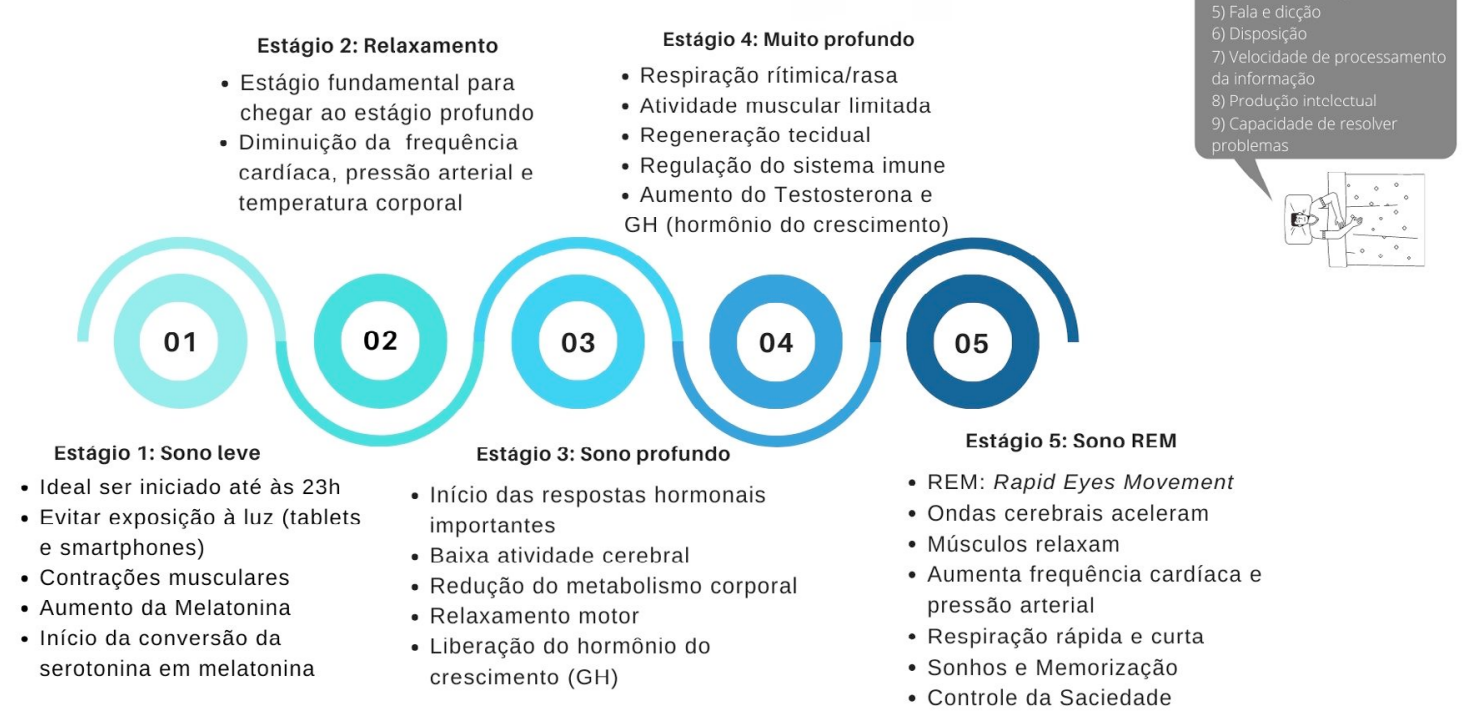

Buscou-se neste infográfico, atender aos princípios do Design da informação definidos por Pettersson (2016). Ao representar a informação de forma clara, simples e organizada de modo a exigir menor esforço cognitivo do leitor, objetivou-se alcançar o que dispõem os princípios cognitivos quanto à facilidade de atenção, percepção, processamento e memória da informação. A simplicidade foi explorada no infográfico tanto a partir do recurso visual, como a partir da busca por um texto conciso, limitando-se às características de cada estágio do sono. Cairo (2016) pontua que por vezes os infográficos são organizados de forma a explicar narrativas e eventos sequenciais, o que corresponde, por exemplo, à representação dos estágios do sono.

Recursos visuais, como cores e formas, juntamente com recursos tipográficos, como uso do negrito, contribuíram para a aplicação do princípio da ênfase ao destacar cada estágio do sono e possibilitar que o leitor recuperasse as informações dos estágios de forma fácil e rápida. A utilização de diferentes tons de azul foi baseada na psicologia das cores, estudada por Heller (2013). O efeito calmante e a associação da cor a contextos que remetem ao sono, como por exemplo dormitórios, são alguns dos significados que a autora relaciona à cor azul.

\section{Discussão e resultados}

Para avaliar o interesse dos participantes com relação ao conteúdo apresentado, bem como a percepção de compreensão e o design da informação, foram elaboradas três questões com 
opções de respostas, em escala visual de 1 a 5 , as quais obtiveram os índices médios da tabela 2 como resultado:

Tabela 2: Índices de avaliação da representação da informação. Elaborada pelas autoras.

\begin{tabular}{lcc}
\hline Pergunta do questionário & \multicolumn{2}{c}{ Representação da Informação } \\
& Texto & Infográfico \\
\hline $\begin{array}{l}\text { Qual o seu grau de interesse pelas informações apresentadas no } \\
\text { arquivo? }\end{array}$ & 4,2 & 4 \\
\hline $\begin{array}{l}\text { Como você avalia o seu nível de compreensão das informações } \\
\text { apresentadas no arquivo? }\end{array}$ & 4,6 & 4,4 \\
\hline $\begin{array}{l}\text { Qual a sua avaliação sobre a apresentação do conteúdo, } \\
\text { considerando aspectos como a organização, legibilidade e } \\
\text { estética das informações apresentadas? }\end{array}$ & 3,4 & 4,4 \\
\hline
\end{tabular}

Observou-se que tanto o interesse pelas informações quanto o nível de compreensão do conteúdo mantiveram médias muito próximas entre as duas representações, com uma pequena diferença positiva para a representação em formato exclusivamente textual. A avaliação sobre a apresentação do conteúdo, no entanto, revelou uma preferência de 1 ponto superior para a informação apresentada em forma de infográfico. O item considerou aspectos como a organização, legibilidade e estética das informações.

Com relação ao item "as informações apresentadas despertaram o meu interesse em aprofundar a leitura sobre os benefícios e ciclo do sono", os dois grupos apresentaram reações análogas, em termos numéricos, ou seja, tanto para o grupo que leu o texto quanto para o grupo que leu o infográfico, $60 \%$ dos participantes de cada grupo concordou parcialmente que as informações apresentadas despertaram algum tipo de interesse, $20 \%$ concordou totalmente e outros $20 \%$ discordou totalmente.

Considerando que os dados não retrataram diferença no nível de interesse, a partir das distintas representações da informação, outros fatores devem ser observados. Frascara (2011) cita a motivação do leitor como um dos fatores adicionais importantes, o que nos permite inferir que a existência de um interesse prévio sobre a informação, neste caso relacionada ao ciclo do sono, seja um motivador da leitura, para a maioria dos participantes (80\%).

Os dados qualitativos também trouxeram relatos que apontam para o interesse e a relevância do conteúdo. No entanto, críticas objetivas à informação representada somente por texto, mais especificamente quanto a sua extensão, foram registradas. Nas palavras de um participante:

"A informação apresentada é de interesse de todo mundo, pois permeia a vida de todos. No entanto, a maneira como ela foi apresentada, com textos longos e com parágrafos extensos, faz com que o conteúdo seja menos apropriado pelo leitor". 
A apresentação de textos longos, citada no comentário, remete ao princípio da simplicidade. De acordo com Pettersson (2016), estabelecer simplicidade em texto, ilustrações e forma gráfica é, provavelmente, um dos mais importantes princípios do design da informação.

Além de extenso, o texto foi considerado pouco atrativo e de leitura cansativa, o que originou menção ao infográfico como uma solução referenciada por participantes da pesquisa, dentre àqueles que receberam a informação representada apenas em texto:

"Com o devido respeito, o próprio texto dá sono. É longo, não traz nenhum conforto visual para o leitor. Restringe-se ao texto, sendo que poderia utilizar imagens, infográficos e uma linguagem dialógica para deixá-lo mais leve e direto".

"Acho que a informação poderia ter sido apresentada, também, de forma mais visual, não apenas textual. Fica um pouco cansativo ter apenas texto".

O conforto visual também é associado à legibilidade da informação, aspecto trabalhado pelo princípio da clareza, conforme explica Pettersson (2016): "Uma mensagem tem boa legibilidade se for fácil de ler e se o leitor puder ver e distinguir facilmente todas as diferentes partes da mensagem" (Pettersson, 2016, p 65).

Para a informação representada na figura 2, observa-se, ainda, a ausência de um dos objetivos, previstos na ISO 9241, como indicador de usabilidade: a satisfação. Percebe-se pelas respostas qualitativas a presença de desconforto na leitura e a ausência de atitudes positivas. O trecho do comentário "poderia utilizar imagens, infográficos e uma linguagem dialógica" corrobora com as indicações de uso das informações visuais, apontadas por Marsh (1983), que sugerem a priorização de informações visuais para facilitar a compreensão em situações como quando a mensagem é complexa, muito extensa ou quando o ambiente é barulhento.

Os diferentes tipos de representação da informação também não indicaram interferências relevantes com relação ao item que mencionou a possibilidade de mudança comportamental ou de atitudes relacionadas ao sono, a partir da leitura das informações apresentadas. Ou seja, os dados não revelaram influência do tipo de representação da informação no uso da informação. Neste ponto, cabe resgatar o que Wolf (2019) coloca sobre o fato da atenção estar recortada em intervalos mais curtos, o que interfere no desenvolvimento de pensamentos mais profundos e, possivelmente, na apropriação e uso efetivo da informação.

O uso da informação é observado como um indicativo de eficácia. Frascara (2011) salienta que a gestão da informação não termina com a interpretação e que no design da informação, geralmente, as pessoas não devem apenas entender as mensagens: elas também devem agir. Nesse sentido, sobre a possibilidade de alteração dos hábitos relacionados ao sono, após a leitura das informações, os dois grupos tiveram, igualmente, $60 \%$ de respostas no item "concordo parcialmente". Para este item, é importante resgatar que Frascara (2011) aponta o repertório individual e o perfil de cada usuário como grandes influenciadores na intenção de mudança de hábitos ou comportamento.

A maior disparidade entre as respostas dos dois grupos que participaram do estudo ocorreu no item que abordou a interferência da forma de apresentação da informação na facilidade de 
leitura e estímulo do interesse do leitor. Sessenta por cento dos respondentes do grupo que leu a informação representada na figura 2, concordou totalmente com esta relação. Para os outros $40 \%$ do grupo, ou seja, dois participantes, um deles discordou totalmente e outro parcialmente da afirmação que relaciona a forma de apresentação e a facilidade de leitura. Já para o grupo que acessou o infográfico (figura 3), 4 participantes (80\%) concordaram totalmente ou parcialmente com a afirmação e 1 participante discordou parcialmente.

Os dados quantitativos são reforçados pelos dados qualitativos quando se verifica relatos para a informação representada por meio de infográfico (figura 3 ) relacionados diretamente com a facilidade da leitura como, por exemplo: "Conteúdo muito bem organizado, de fácil leitura e entendimento" ou "[...] conteúdo bem detalhado e de fácil compreensão [...]".

Com relação à memorização e retenção da informação apresentada, a pergunta " Em que estágio ocorre o início do sono profundo, caracterizado pela baixa atividade cerebral, relaxamento motor e liberação do hormônio do crescimento (GH)" obteve igual índice de acertos nos dois grupos, $60 \%$ dos participantes de cada grupo respondeu corretamente.

Dessa forma, os resultados não apontaram o uso do infográfico ou do texto como um diferencial na retenção da informação. Entretanto, cabe destacar o tempo utilizado para finalização do preenchimento das respostas (Gráfico 1). O grupo que leu a informação representada somente por textos (figura 1) utilizou, em média, 9 minutos e 5 segundos. Já o grupo que analisou a informação representada por infográfico (figura 2) finalizou o preenchimento do questionário em um tempo médio de 4 minutos e 18 segundos. O resultado reforça que a simplicidade em uma mensagem resultará em percepção, processamento e memória mais fácil e eficiente. "Frases complexas e longas requerem maior capacidade cognitiva para serem processadas mentalmente do que frases curtas e simples" (Pettersson, 2016, p 65).

Gráfico 1: Tempo médio gasto para resposta ao questionário

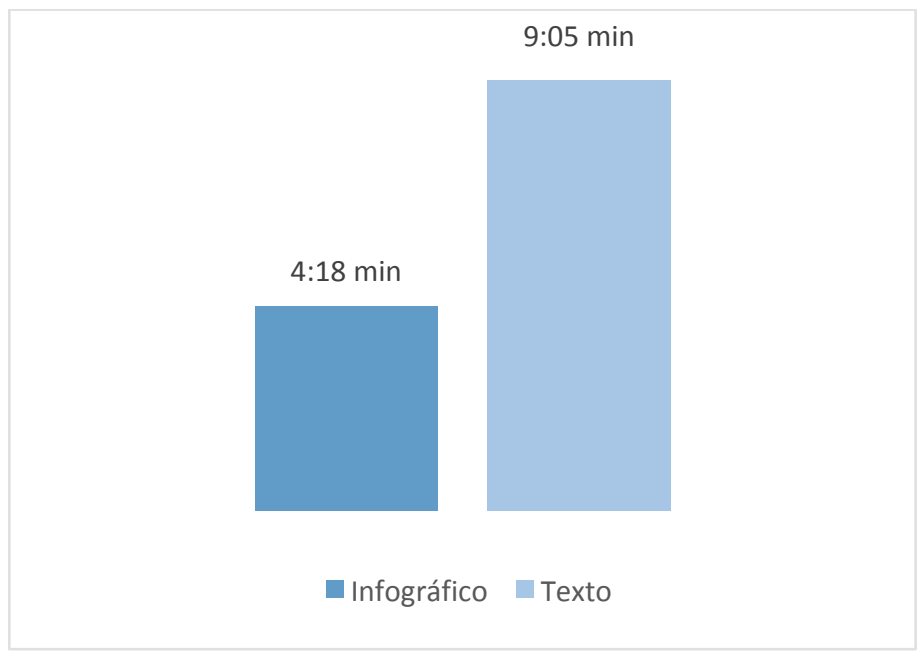


Considerando a abordagem de eficiência, apresentada na ISO 9241, que a define como "recursos gastos em relação à acurácia e abrangência com as quais usuários atingem objetivos", os resultados relacionados ao tempo de resposta, aferido durante a pesquisa, apontam para a maior eficiência na leitura da informação representada pelo infográfico. Os dois grupos obtiveram o mesmo percentual de acertos na questão que aferiu a retenção da informação. No entanto, o tempo médio gasto pelo grupo que teve acesso à informação visual para preenchimento de todo o instrumento foi $53 \%$ menor do que o tempo médio gasto pelo grupo que acessou à informação textual.

Diante dos dados e tendo em vista que todos os participantes concluíram o preenchimento total do questionário, com igual número de acertos para a questão que avaliou a retenção e compreensão de parte da informação, os resultados sugerem uma maior eficiência da informação representada por meio de um infográfico.

Ademais, os dados qualitativos demonstraram a preferência dos participantes pela representação visual devido, principalmente, à facilidade da leitura. Esta predileção corrobora com estudos que apontam, segundo Liu (2005), para um "novo normal" onde ler digitalmente é "ler por cima". Wolf (2019) complementa e aponta a leitura superficial como um processo que envolve simplificar, processar a informação o mais rápido possível e selecionar. O que significa ler mais em espasmos menores com o intuito de aliviar a sobrecarga cognitiva ocasionada por múltiplos dispositivos.

\section{Considerações finais}

Este artigo sugere que a utilização de recursos visuais para a informação digital sobre saúde e bem-estar, em ambientes organizacionais, facilita a leitura e, principalmente, requer um período de tempo menor para a compreensão da informação.

Em linhas gerais, o estudo aponta que, para o contexto analisado, ou seja, em um ambiente organizacional digital, o usuário prefere realizar a leitura de informações sobre saúde e bemestar por meio de um infográfico, com a combinação de textos e recursos visuais. A preferência dos leitores justifica-se pelo fato de tornar a leitura menos cansativa e mais objetiva.

O estudo da influência do Design na leitura da informação digital sobre saúde e bem-estar mostrou que, além da satisfação do usuário, a informação apresentada em formato de infográfico reportou maior eficiência na leitura, com menor período de tempo gasto e resultados iguais ou similares aos observados na leitura da informação apresentada somente por meio de texto corrido.

No contexto pesquisado, as informações sobre saúde e bem-estar competem pela atenção do usuário com informações relacionadas diretamente às demandas das atividades organizacionais diárias. Assim, a informação que apresenta elementos que facilitam a leitura demanda menor tempo para sua apreensão, tornando-se mais atraente ao leitor. Desta forma, pode-se inferir que informações sobre saúde e bem-estar apresentariam maior chance de serem lidas quando apresentadas a partir da utilização de elementos visuais. 
Nesse sentido, o Design da informação pode contribuir para este novo cenário de explosão informacional muito além da entrega de informações planejadas e organizadas com clareza, objetividade e harmonia para o leitor. Cooperar para o que Wolf (2019) chama de 'paciência cognitiva' e auxiliar na real apropriação da informação em meio ao excesso de estímulos pode ser o novo papel do Design da informação. Fazer com que a informação relevante ou, no caso deste estudo, que agregue conhecimentos sobre saúde e bem-estar, encontre usuários que estão mergulhados ou perdidos em meio a estimulantes digitais pode ser mais um papel de áreas do conhecimento que exploram o fenômeno da informação, como o Design e a Ciência da informação.

\section{Referências}

ABNT. (2002). Associação Brasileira de Normas Técnicas. NBR 9241-11. Requisitos Ergonômicos para Trabalho de Escritórios com Computadores. Parte 11 - Orientações sobre Usabilidade. Rio de Janeiro.

Araújo, C. A. A. (2018). O que é ciência da informação. Belo Horizonte: KMA.

Cairo, A. (2016). The Truthful Art: Data, Charts, and Maps for Communication. New Riders.

Capurro, R., \& Hjørland, B. (2007). O conceito de informação. Perspectivas em Ciência da Informação, Belo Horizonte, v. 12, n. 1, p. 148-207.

Crary, J. (2014). 24/7 - Capitalismo tardio e os fins do sono. São Paulo: Cosac Naify.

Davenport, T. H. (1998). Ecologia da informação: por que só a tecnologia não basta para o sucesso na era da informação. São Paulo: Futura.

Eysenbach, G., \& Kohler, C. (2002). How to consumers search for and appraise health information on the world wide web? Qualitative study using focus groups, usability tests, and in-depth interviews. BMJ, v. 324, p. 573-577.

Frascara, J. (2011). ¿qué es el diseño de información?. Buenos Aires: Ediciones Infinito

Han, B. (2016). No Enxame: Reflexões sobre o Digital. Lisboa: Relógio D’Água Editores.

Heller, E. (2013). A psicologia das cores: como as cores afetam a emoção e a razão. São Paulo: Editorial Gustavo Gili.

Jacko, Julie A. (2012). Human Computer Interaction Handbook : Fundamentals, Evolving Technologies, and Emerging Applications, Third Edition. Boca Raton: Taylor \& Francis Group.

Lima, R. C. (2015). O que é infografia jornalística?. Infodesign, São Paulo, v. 12, n.1, p. 111 127.

Liu, Z. (2005). Reading behavior in the digital environment: Changes in reading behavior over the past ten years. J. Documentation 61: 700-712.

Lopez, I. L. (2004). Novos paradigmas para avaliação da qualidade da informação em saúde recuperada na web. Revista Ciência da Informação - IBICT. Vol. 33, N. 1.

Marsh. P. O. (1983). Messages that work: a guide to communication design. Englewood Cliffs, New Jersey. Educational Technology Publications. 
Márquez, I. (2018). Móviles 24/7: el teléfono móvil en la era de la hiperconectividad, Editorial UOC.

Miranda F. \& Andrade R, C. (2017). Pensar Infográfico: uma proposta de ensino introdutório de infografia sob a perspectiva da linguagem gráfica. Infodesign. São Paulo. V. 14, n. 3, p. 374 $-396$.

Nassau, Felipe. [Felipe Nassau - Trust Sports]. (2019, junho 9). Perda de gordura saudável, massa muscular e saúde - Mitos e Verdades [vídeo]. Retirado de https://www. youtube.com/watch?v=u-2BXofrcRA\&t=4198s

Nielsen, J. (1993). Usability Engeneering. San Francisco: Morgan Kaufmann.

Petterson, R. Information design: an introduction. (2002). Amsterdam/Philadelphia:John Benjamins Publishing Company.

Pettersson, R. (2016). Information design theories. IIID Public Library. Tullinge.

Wolf, M. (2019). O Cérebro no mundo digital: os desafios da leitura na nossa era. Tradução de Rodolfo llari. São Paulo: Contexto.

Wurman, R. S. (1991). Ansiedade de Informação: como transformar informação em compreensão. São Paulo: Cultura.

\section{Sobre as autoras}

Fernanda Rodrigues Bertoldo, Mestranda em Ciência da Informação, UnB, Brasil

$<$ fernandabertoldo@gmail.com>

Ivette Kafure Muñoz, Dra., UnB, Brasil <ivettek@unb.br>

Ana Mansur de Oliveira, Dra., UnB, Brasil <anamansur@gmail.com>

Virgínia Tiradentes Souto, PhD, UnB, Brasil <v.tiradentes@gmail.com> 